\title{
EFEKTIVITAS BIMBINGAN KELOMPOK TEKNIK DISKUSI UNTUK MENINGKATKAN PEMAHAMAN TUGAS PERKEMBANGAN SISWA
}

\author{
Hermawan dan Eko Perianto \\ Bimbingan dan Konseling, Fakultas Keguruan dan Ilmu Pendidikan, \\ Universitas PGRI Yogyakarta \\ hermawansupendi@gmail.com, ekoperianto@gmail.com
}

\begin{abstract}
ABSTRAK
Tujuan dari penelitian ini yaitu untuk mengetahui kondisi pemahaman tugas perkembangan siswa kelas XI IPA SMAN 1 Gamping tahun pelajaran 2017/2018. Desain penelitian yang digunakan dalam penelitian ini yaitu Pre-experimental desain dengan jenis one group pre-test post-test desain. Subjek penelitian yaitu kelas XI IPA SMA N 1 Gamping yang berjumlah 11 siswa yang dipilih dengan metode purpouse sampling. Metode pengumpulan data dalam penelitian ini menggunakan angket teknik analisa data dengan menggunakan teknik analisis data dengan teknik analisis statistik paired sampel t-test. Hasil penelitian menunjukkan hipotesis terbukti bahwa layanan bimbingan kelompok teknik diskusi efektif untuk meningkatkan pemahaman tugas perkembangan pada siswa kelas XI SMA N 1 Gamping tahun pelajaran 2017/2018. Dari hasil uji paired sampel $t$-tes dilakukan diperoleh nilai $\mathrm{t}=-3,188$ dengna nilai $\mathrm{p}=0,010<0,05$ yang berarti ada peningkatan pemahaman tugas perkembangan siswa antara sebelum dan sesudah diberikan treetmen bimbingan kelompok dengan teknik diskusi. Hal tersebut menunjukkan pemberian bimbingan kelompok menggunakan teknik diskusi efektif dalam meningkatkan pemahaman tugas perkembangan siswa.
\end{abstract}

Kata kunci: bimbingan kelompok, teknik diskusi, pemahaman tugas perkembangan

\section{ABSTRACT}

The purpose of this study is to find out the condition of understanding the developmental tasks of class XI students of SMAN 1 Gamping science school year 2017/2018. The research design used in this study is Pre-experimental design with one group pre-test post-test design. The research subjects were class XI IPA N 1 Gamping High School, amounting to 11 students selected by purposive sampling method. The method of data collection in this study used questionnaire data analysis techniques using data analysis techniques with statistical analysis techniques paired sample t-test. The results of the study show that the hypothesis is proven that group guidance services are effective discussion techniques to improve understanding of development tasks in class XI students of SMA 1 Gamping in the academic year 2017/2018. From the results of the paired sample ttest it was obtained that the value $t=-3,188$ with a value of $p=0.010<0.05$, which means there is an increase in understanding of students' developmental tasks between before and after being given group guidance treetmen with discussion techniques. This shows that the provision of group guidance uses effective discussion techniques in improving the understanding of students' development tasks. 
Keywords: group guidance, discussion techniques, understanding of developmental tasks

\section{Pendahuluan}

Pelayanan bimbingan dan konseling sekolah di era sekarang ini bermuara pada pencapaian tugas perkembangan peserta didik. Layanan yang diberikanpembimbing pada hakikatnya merupakan upaya membantu peserta didik mencapai tugas perkembangan yang diembannya. Dengan kata lain, pelaksanaan program bimbingan dan konseling saat ini bukan lagi didasarkan pada pemahaman masalah, melainkan kesadaran akan pentingnya pencapaian tugas perkembangan peserta didik.

Pandangan baru pelaksanaan bimbingan dan konseling ini dapat ditemukan pada Panduan OperasionalPenyelenggaraan Bimbingan dan Konseling (POP BK) yang diterbitkan oleh Direktorat Jenderal Guru dan Tenaga Kependidikan tahun 2017. Dalam panduan operasional tersebut, dijelaskan bahwa penyusunan program bimbingan dan konseling didasarkan pada hasil identifikasi kebutuhan perkembangan peserta didik. Sehingga upaya pemahaman terhadap tugas perkembangan peserta didik adalah hal yang mutlak harus dilakukan sebelum menyusun program bimbingan dan konseling.

Kondisi diatas tentunya menuntut semua pihak untuk berusaha memahami tugas perkembangan peserta didik, bukan hanya pembimbing, tetapi salah satunya yaitu peserta didik itu sendiri. Peserta didik sebagai subjek utama layanan bimbingan dan konseling disekolah perlu memahami tugas perkembangannya. Dengan bekal pemahaman tersebut, diharapkan peserta didik akan lebih mudah dalam mencapai dan menuntaskan tugas perkembangan pada setiap tahap kehidupannya sehingga mereka bisa berkembang menjadi pribadi yang bahagia dan mandiri.Yusuf (2011:65) menyebutkan apabila individu berhasil menuntaskan tugas perkembangannya, maka ia akan mencapai kebahagiaan dan kesuksesan pada tugas perkembangan berikutnya. Sebaliknya jika seseorang gagal menuntaskan tugas perkembangannya, maka akan menyebabkan permasalahan pada diri individu yang bersangkutan, menimbulkan penolakan masyarakat, dan kesulitan menuntaskan tugas perkembangan selanjutnya. 
Berdasarkan permasalahan diatas, maka kami tertarik untuk mencari strategi layanan yang tepat dan efektif untuk meningkatkan pemahaman peserta didik terhadap tugas perkembangan yang diembannya. Dalam hal ini kami memiliki ketertarikan untuk memahami lebih dalam mengenai layanan bimbingan kelompok yang diberikan kepada siswa dengan menggunakan teknik diskusi kelompok.

Teknik diskusi merupakan salah satu teknik dalam layanan bimbingan kelompok. Teknik ini memberikan kesempatan kepada siswa untuk mengkaji suatu topik permasalahan secara bersama-sama dengan memanfaatkan dinamika kelompok. Berkenaan dengan hal tersebut, Prayitno (1995:23) menegaskan peran dinamika kelompok yaitu "sebagai jiwa yang menghidupkan kelompok", sehingga dengan kegiatan diskusi memungkinkan peserta didik untuk secara aktif berkomunikasi dengan anggota kelompok lain serta bertukar gagasan yang pada akhirnya siswa akan memiliki tingkat pemahaman yang baik terhadap suatu permasalahan yang sedang dibahas.

Adapun kaitannya dengan tingkatan usia, maka peserta didik pada jenjang SMA merupakan kategori usia remaja. Usia remaja merupakan usia pada rentang 12-21 tahun yang disebut sebagai masa "badai dan tekanan jiwa", karena pada usia ini individu mengalami perubahan fisik, intelektual dan emosional yang signifikan (Hurlock, 1980:207).

Peserta didik yang berada pada jenjang SMA merupakan individu dengan karakteristik yang dinamis, mereka perlu diimbangi dengan berbagai pemahaman yang baik terutama mengenai tugas perkembangan. Hal ini penting agar mereka dapat terhindar dari berbagai permasalahan yang ditimbulkan dari ketidakberhasilan menuntaskan tugas-tugas perkembangan yang mereka miliki. Seperti yang ditegaskan Yusuf (2015:3) bahwa "ketidak tercapaiannya tugas perkembangan akan memunculkan masalah...”. Upaya meningkatkan pemahaman peserta didik terhadap tugas perkembangannya tentunya perlu ditempuh melalui layanan bimbingan dan konseling dengan teknik yang tepat. 
Berdasarkan pemaparan diatas, maka peneliti merasa perlu untukmelakukan penelitian mengenai "Efektivitas Bimbingan Kelompok dengan Teknik Diskusi untuk Meningkatkan Pemahaman Tugas Perkembangan pada Siswa Kelas XI IPA SMAN 1 Gamping Tahun Pelajaran 2017/2018” agar didapatkan data yang dapat

dipertanggungjawabkan dalam menunjang peningkatan kualitas bimbingan dan konseling di lingkungan SMAN 1 Gamping secara khusus serta bimbingan dan konseling pada umumnya. Berdasarkan uraian pada latar belakang masalah diatas, maka perumusan masalah pada penelitian ini yaitu sebagai berikut: Apakah bimbingan kelompok dengan teknik diskusi efektif untuk meningkatkan pemahaman tugas perkembangan pada siswa kelas XI IPA SMAN 1 Gamping tahun pelajaran 2017/2018?

Berdasarkan ruang lingkup permasalahan sebagaimana dirumuskan diatas, maka penelitian ini bertujuan untuk: (1) Mengetahui kondisi pemahaman tugas perkembangan siswa kelas XI IPA SMAN 1 Gamping tahun pelajaran2017/2018sebelumdiberikan layanan bimbingan kelompok dengan teknik diskusi. (2) Menguji efektivitas bimbingan kelompok dengan teknik diskusi untuk meningkatkan pemahaman tugas perkembangan siswa kelas XI IPA SMAN 1 Gamping tahun pelajaran 2017/2018.

\section{Metode Penelitian}

Menurut Arikunto (2013:169), variabel adalah gejala yang bervariasi yang menjadi objek penelitian. Sedangkan menurut Sugiyono (2011:38) variabel adalah atribut seseorang atau objek yang mempunyai variasi antara satu orang dengan yang lain atau satu objek dengan objek lain. Sehingga dapat dipahami bahwa varaiabel penelitian adalah segala sesuatu yang berbentuk apa saja yang ditetapkan oleh peneliti untuk dipelajari sehingga diperoleh informasi tentang hal tersebut kemudian ditarik kesimpulannya.

Pada penelitian ini, terdapat dua varaibel yakni varaibel beas dan variabel terikat. Variabel bebas adalah variabel yang mempengaruhi atau yang menjadi sebab perubahan atau timbulnya variabel terikat sedangkan variabel terikat 
merupakan variabel yang dijelaskan atau dipengaruhi oleh variabel bebas (Sugiyono 2011:39). Variabel bebas pada penelitian ini yaitu "bimbingan kelompok dengan teknik diskusi”. Seperti yang telah dibahas pada kajian teori diatas, bahwa yang dimaksud bimbingan kelompok adalah proses pemberian bantuan yang diberikan kepada individu guna mengembangkan potensi secara

maksimal dengan cara memberi informasi, diskusi dan memanfaatkan dinamika kelompok. Adapun yang dimaksud variabel terikat pada penelitian ini yaitu “pemahaman tugas perkembangan". Pemahaman tugas perkembangan adalah suatu tingkatan pemikiran untuk mengerti atau memahami tugas perkembangan yang dimiliki.

Dalam penelitian ini yang menjadi sampel adalah siswa yang memiliki pemahaman tugas perkembangan yang tergolong rendah berdasarkan hasil pretest, siswa tersebut merupakan subjek sekaligus sumber data penelitian yang mendapatkan treatement dengan teknik yang telah ditentukan yaitu teknik diskusi. Pada penelitian ini peneliti menggunakan teknik purposive sampling (pengambilan sampel berdasarkan tujuan). Dalam hal ini peserta didik diberikan skala pemahaman tugas perkembangan yang berupa angket pernyataan, kemudian akan diperoleh peserta didik dengan pemahaman tugas perkembangan rendah. Skala pemahaman tugas perkembangan berfungsi menjaring peserta didik yang memiliki pemahaman tugas perkembangan rendah melalui pre-tes untuk mendapatkan sampel penelitian dengan kriteria yang telah ditentukan, kemudian akan diberikan layanan bimbingan kelompok dengan teknik diskusi sebagai treatment.

Menurut Arikunto (2013:203), instrumen penelitian adalah alat atau fasilitas yang digunakan oleh peneliti dalam mengumpulkan data agar pekerjaan lebih mudah dan hasilnya lebih baik, dalam arti lebih cermat, lengkap dan sistematis sehingga mudah diolah. Dalam hal ini instrumen penelitian yang digunakan peneliti yaitu instrumen angket dengna jumlah 23 butir item pernyataan. Sugiyono (2011:147) menjelaskan bahwa analisis data yaitu mengelompokan data berdasarkan jenis data dan variabel, mentabulasi data berdasarkan varaibel dari 
seluruh responden, menyajikan data dari setiap variabel yang diteliti, melakukan pergitungan untuk menjawab rumusan masalah dan melakukan perhitungan untuk menguji hipotesis yang telah diajukan. Analisis data dalam penelitian ini yaitu menggunakan uji t-test atau lebih tepatnya Paired Sample T-test dengan bantuan program SPSS (Statistical Product and Service Solution) for windows version 16.

\section{Hasil dan Pembahasan}

Kondisi pemahaman siswa sebelum diberikan layananan atau treatment yaitu sebagai berikut: pada kategori tinggi 32 persen, kategori sedang 68 persen, kategori rendah nol persen dan kategori sangat rendah nol persen. Data tersebut menunjukan bahwa mayoritas pemahaman tugas perkembangan siswa sebelum diberikan layanan yaitu berada pada kategori sedang. Adapun yang dimaksud dengan "kategori sedang" dijelaskan melalui ciri-ciri sebagai berikut (Wasito, 2016:4)

1. Mempunyai peran yang netral dalam kegiatan kelompok.

2. Memiliki seorang teman dekat.

3. Mampu mengarahkan diri dalam memelihara kesehatan, namun tidak dalam waktu lama.

4. Sikapnya belum ajeg antara desakan untuk menjadi dewasa dengan sikap kekanak-kanakan.

5. Remaja mempunyai minat atau perahatian terhadap masalah filosofis dan kegamaan.

Dalam rangka menentukan mana saja siswa yang terpilih sebagai sampel penelitian, maka peneliti menetapkan skor tertinggi sebesar 70. Skor tersebut ditetapkan untuk membatasi jumlah siswa yang terpilih sebagai sampel. Setiap siswa yang skor pemahaman tugas perkembangannya lebih kecil atau sama dengan 70 maka siswa tersebut dinyatakan memenuhi kriteria untuk dijadikan sampel penelitian, kemudian dengan memperhatian kesiapan siswa, maka ditetapkanlah 11 siswa sebagai sampel penelitian. 
Setelah ditetapkan siswa yang menjadi sampel penelitian, langkah selanjutnya yaitu memberikan treatment berupa bimbingan kelompok dengan teknik diskusi. Dalam penelitian ini treatment diberikan sebanyak 2 kali dengan alokasi waktu 1 x 45 menit per pertemuan.

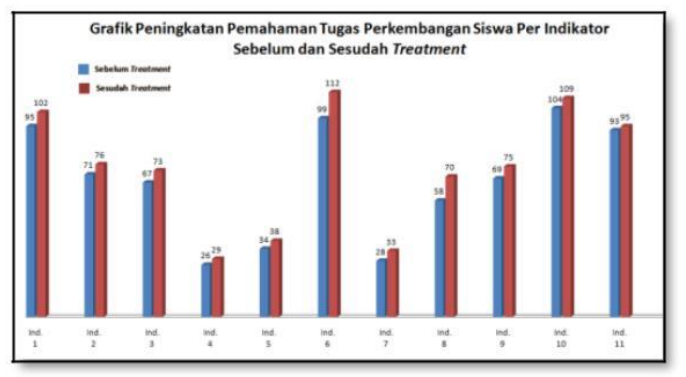

Kondisi pemahaman siswa setelah diberikan layanan peningkatan pemahaman tugas perkembangan siswa berdasarkan indikator. Skor pemahaman tugas perkembangan siswa setelah diberikan treatment lebih tinggi dibandingkan dengan skor sebelum treatment pada seluruh indikator tugas perkembangan.

Berdasarkan hasil analisis uji paired sampel t-test diperoleh nilai t sebesar 3,188 dengan signifikansi 0,010 lebih kecil dari 0,05 (p 0,010<0,05). Nilai tersebut menunjukan bahwa terdapat perbedaan signifikan antara pemahaman tugas perkembangan siswa sebelum diberikan treatment dengan setelah treatment.

Penelitian ini berjudul "Efektivitas Bimbingan Kelompok dengan Teknik Diskusi untuk Meningkatkan Pemahaman Tugas Perkembangan pada Siswa Kelas XI IPA SMAN 1 Gamping Tahun Pelajaran 2017/2018”. Penelitian ini termasuk kedalam penelitian kuantitatif dengan pendekatan penelitian eksperimen yakni pre eksperimental design (eksperimen semu) dengan jenis one group pre-test post-test design yaitu eksperimen yang dilakukan pada satu kelompok saja tanpa adanya kelompok kontrol.

Peningkatan pemahaman siswa terhadap tugas perkembangan juga dapat dipahami dari hasil uji paired sample t-test diatas, hasilnya menunjukan nilai $\mathrm{t}$ hitung sebesar -3.188 sedangkah $\mathrm{t}$ tabel sebesar -2.288 yang artinya bahwa nilai $-\mathrm{t}$ 
hitung lebih kecil dari -t tabel sehingga Ho ditolak yang menandakan ada perbedaan pemahaman yang signifikan setelah siswa diberikan layanan bimbingan kelompok dengan teknik diskusi. Jadi dari hasil analisis diatas dapat disumpulkan bahwa hipotesis penelitian yang berbunyi "Bimbingan kelompok dengan teknik diskusi efektif untuk meningkatkan pemahaman tugas perkembangan pada siswa kelas XI IPA SMAN 1 Gamping tahun pelajaran 2017/2018” diterima.

\section{Kesimpulan}

Berdasarkan analisis data dalam penelitian ini, maka dapat ditarik kesimpulan yaitu (1) Analis data dengan uji paired sample t-test menunjukan nilai sebesar -3,188 dengan $\mathrm{p} 0.010$ yang artinya $\mathrm{p}<0,05$ menandakan bahwa hipotesis alternatif yang menyatakan ada perbedaan signifikan pada pemahaman siswa antara sebelum diberikan treatment berupa layanan bimbingan kelompok dengan teknik diskusi dengan setelah diberikan treatment dapat diterima.(2)Secara keseluruhan penelitian ini menghasilkan kesimpulan bahwa bimbingan kelompok dengan teknik diskusi efektif untuk meningkatkan pemahaman tugas perkembangan pada siswa kelas XI IPA SMAN 1 Gamping tahun pelajaran 2017/2018.

\section{Daftar Pustaka}

Desmita. 2013. Psikologi Perkembangan. Bandung: PT. Remaja Rosdakarya.

Dewa Ketut Sukardi. 2008. Pengantar Pelaksanaan Program Bimbingan dan Konseling di Sekolah. Jakarta: Rineka Cipta.

Eko Putro Widoyoko. 2018. Penilaian Hasil Pembelajaran di Sekolah Edisi Revisi. Yogyakarta: Pustaka Pelajar.

Hurlock. Elizabeth B. 1980. Psikologi Perkembangan. Jakarta: Erlangga.

Prayitno. 1995. Bimbingan dan Konseling Kelompok. Jakarta: Ghalia Indonesia.

Prayitno, dan Amti E. 2013. Dasar-Dasar Bimbingan dan Konseling. Jakarta: Rineka Cipta.

Suharsimi Arikunto. 2006. Prosedur Penelitian. Jakarta: Rineka Cipta. 
2013. Prosedur Penelitian Suatu Pendekatan Praktik. Jakarta: Rineka Cipta.

Sugiyono, 2011. Metode Penelitian Pendidikan: Pendekatan Kuantitatif, Kualitatif, dan R\&D Cet. XIII. Bandung: Alfabeta.

2015. Metode Penelitian Pendidikan: Pendekatan Kuantitatif, Kualitatif, dan R\&D Cet. XIV. Bandung: Alfabeta.

Syamsu Yusuf. 2010. Landasan Bimbingan dan Konseling. Bandung: PT. Remaja Rosdakarya.

. 2011. Psikologi Perkembangan Anak dan Remaja. Bandung: PT. Remaja Rosdakarya.

Rizqi Press.

2015. Program Bimbingan dan Konseling di Sekolah. Bandung.

Tatiek Romlah. 2006. Teori dan Praktik Bimbingan Kelompok. Malang: UM.

Tohirin. 2013. Bimbingan dan Konseling di Sejokah dan Madrasah (Berbasis Integrasi). Jakarta: Rajawali Pers.

Winkel. dan Sri Hastuti. 2013. Bimbingan dan Konseling di Institiusi Pendidikan.Yogyakarta: Media Abadi.

Direktorat Jenderal Guru dan Tenaga Kependidikan. 2017. Panduan Operasional Penyelenggaraan Bimbingan dan Konseling Sekolah Menengah Atas (SMA). Jakarta: Kementerian Pendidikan dan Kebudayaan. 